second pregnancy ended with the birth of a healthy son. The third child died on the first day of life in severe respiratory distress. Like her sister, she was mildly growth retarded with a birth weight $(2820 \mathrm{~g})$ and head circumference $(32.5 \mathrm{~cm})$ between the 10th and 25 th centiles. Body length $(50.5 \mathrm{~cm})$ and foot length $(8.1 \mathrm{~cm})$ were normal. Clinical, radiological, and pathological findings were exactly the same as in case 1 . The combined lung weight was $18.9 \mathrm{~g}$, with a lung weight/body weight ratio of 0.0067 . The karyotype was normal.

Pulmonary hypoplasia is a common cause of intractable neonatal respiratory distress. As a rule, pulmonary hypoplasia is not a primary malformation but a secondary deformation. ${ }^{1}$ Thus, the lung anlagen and initial organogenesis are normal, until a mechanical factor interferes with development, which thereafter proceeds abnormally. Secondary pulmonary hypoplasia is usually caused by one of the following conditions: prolonged oligohydramnios, diaphragmatic anomalies, skeletal dysplasia, massive chronic pleural effusions, or neuromuscular disease. ${ }^{2}$ Primary pulmonary hypoplasia, that is, an intrinsic abnormality of the lungs with poor development from the beginning, does exist but is exceedingly rare. It is a diagnosis of exclusion that can only be made after all the known aetiologies of secondary pulmonary hypoplasia have been ruled out. This needs thorough pathological examination, including examination of the central and peripheral nervous system and skeletal muscle tissue.

To date, only a limited number of cases of primary pulmonary hypoplasia have been reported, with both sporadic ${ }^{3-5}$ and familial occurrences. ${ }^{6.9}$ There is a striking lack of uniformity in the histology of these cases. Swischuk et $a l^{4}$ and Langer and Kaufmann described reduced radial alveolar counts without other architectural abnormalities of the alveoli. Surprisingly, Frey $e t a l^{\beta}$ and $\mathrm{Hamel}^{9}$ found severely hypoplastic but histologically normal lungs with normal radial alveolar counts. In our two sibs, the lungs were normally lobed but weighed less than $50 \%$ of the expected value for the gestational age. Histological examination showed an almost complete lack of alveolar development, increased amounts of interstitial connective tissue, and abnormal (dysplastic) bronchial cartilage. While, admittedly, primary pulmonary hypoplasia is a heterogeneous condition, the two cases reported here represent a specific entity. Similar histological findings have been described in only two previous case studies. ${ }^{10}$ We agree with Ruthledge and Jensen ${ }^{10}$ and Chambers ${ }^{11}$ that this lesion represents a severe form of peripheral pulmonary maldevelopment or "acinar dysplasia", rather than pure hypoplasia. Apparently, the lung development was arrested in the early canalicular stage and development of the alveolar tissue did not take place. Stocker ${ }^{12}$ suggested that this form of pulmonary hypoplasia might be included in an expanded classification of cystic adenomatoid malformation of the lung ("type 0").

The aetiology and pathogenesis of pulmonary acinar dysplasia are unknown. The epithelium of the respiratory tract up to the alveolar lining is of foregut endodermal origin. Experimental embryological studies have shown that the sequential branching of the tracheobronchial tree is induced by the splanchnopleural mesoderm..$^{13}$ This leads to the conclusion that acinar dysplasia may be an intrinsic defect of the lung mesoderm. The observation of increased interstitial connective tissue and dysplastic bronchial cartilage in two cases appears to corroborate this. However, pulmonary development is an extremely complicated process, depending upon reciprocal epithelial-mesenchymal interactions. For instance, the developing pulmonary epithelium is the site of growth factors such as epidermal growth factor and transforming growth factor- $\alpha$, which influence differentiation of the mesenchymal compartment and overall organogenesis. More specifically, defects in lung specific transcription factors, such as thyroid specific enhancer binding protein, normally expressed in the developing pulmonary epithelium, have been shown to inhibit normal lung development, resulting in rudimentary cystic lungs. ${ }^{14}$ Thus, we cannot rule out a defect in the epithelial cell compartment as the initial cause of this malformation.

This is the first familial report of pulmonary acinar dysplasia, suggesting an autosomal recessive mode of inheritance for a gene critical for normal lung parenchymal development.

PHILIPPE MOERMAN

Department of Pathology, University Hospital St-Rafaël, Minderbroedersstraat 12, B-3000 Leuven, Belgium

CHRIS VANHOLE HUGO DEVLIEGER

Department of Paediatrics, University Hospital Gasthuisberg, Leuven, Belgium

JEAN-PIERRE FRYNS

Department of Human Genetics, University Hospital Gasthuisberg, Leuven, Belgium

1 Spranger J, Benirschke K, Hall JG, et al. Errors of morphogenesis: concepts and terms. Recommendations of an International Working Group. F Pediatr 1982;100:160-5.

2 Wigglesworth JS. Pathology of the lung in the fetus and neonate, with particular reference to problems of growth and maturation. Histopathology 1987;11:671-89.

3 Mendelsohn G, Hutchins GM. Primary pulmonary hypoplasia. Report of a case with polyhydramnios. Am $\mathcal{F}$ Dis Child 1971;131:1220-3.

4 Swischuk LE, Richardson CJ, Nichols MM, Ingman MJ. Primary pulmonary hypoplasia in the neonate. F Pediatr 1979;95:573-7.

5 Langer R, Kaufmann HJ. Primary (isolated) bilateral pulmonary hypoplasia: a comparative study of radiologic findings and autopsy results. Pediatr Radiol 1986;16:175-9.

6 Boylan P, Howe A, Gearty J, O'Brian NG. Familial pulmonary hypoplasia. Ir $\mathcal{f} \mathrm{Med} S \mathrm{Si}$ 1977;146:179-80.

7 Fraser FC. Personal communication. In McKusick VA. Mendelian inheritance in man. MIM number 265430. Baltimore: The Johns Hopkins University Press, 1992:1666.

8 Frey B, Fleishauer A, Gersbach M. Familial isolated pulmonary hypoplasia: a case report, suggesting autosomal recessive inheritance. Eur Pediatr 1994;153:460-3.

9 Hamel BCJ. Familial primary pulmonary hypoplasia. Eur $\mathcal{F}$ Pediatr 1995;154:336.

10 Ruthledge JC, Jensen P. Acinar dysplasia: a new form of pulmonary maldevelopment. Hum Pathol 1986;17:1290-3.

11 Chambers HM. Congenital acinar aplasia: an extreme form of pulmonary maldevelopment Pathology 1991;23:69-71.

12 Stocker JT. Congenital and developmental diseases. In: Dail DH, Hammar SP, eds. Pulmonary pathology. 2nd ed. New York: SpringerVerlag, 1994:155-90.

13 Wessels NK. Mammalian lung development: interactions in formation and morphogenesis of tracheal buds. F Exp Zool 1970;175:455-66.

14 Kimura S, Hara Y, Pineau T, et al. The Tlebp null mouse: thyroid-specific enhancer-binding protein is essential for the organogenesis of the thyroid, lung, ventral forebrain, and pituitary. thyroid, lung, ventral for
Genes Dev 1996;10:60-9.

\section{Coexistence of Gaucher disease type 1 and Joubert syndrome}

Joubert syndrome (JS) is an autosomal recessive disorder in which cytogenetic, biochemi$\mathrm{cal}$, and molecular markers are unknown. It is a distinct clinicopathological entity, characterised by cerebellar vermis dysgenesis, episodic tachypnoea and apnoea in the neonatal period, jerky eye movements, developmental delay, and hypotonia. Associated features may include agenesis of the corpus callosum, chorioretinal colobomata, renal cysts, congenital hepatic fibrosis, and polydactyly. ${ }^{1}$ The molecular basis of JS has recently been investigated by analysing the WNT1 gene, the human homologue of murine wnt-1, for mutations in patients with JS. It was concluded that WNT1 is not a critical gene for JS. ${ }^{2}$

In contrast to JS, the enzymatic and molecular basis in Gaucher disease (GD), an autosomal recessively transmitted lysosoma storage disorder, has been elucidated. ${ }^{3} \mathrm{GD}$ is caused by a deficiency of glucocerebrosidase activity and the gene is located in chromosome 1q21. Clinically, there are three major variants of GD classified by the age of onset, severity of the visceral symptoms, and by the presence or absence of neurological involvement: type 1, the most common variant has a non-neuronopathic course; type 2 presents in infancy with severe neurological involvement; type 3 usually presents as a severe, slowly progressive neurodegenerative disease. Recently, new neonatal and fetal subtypes with a severe course have been described. ${ }^{4}$ In this human subtype and in murine models a total disruption of the glucocerebrosidase gene caused the fulminant disease. ${ }^{5}$ More than 50 different mutations in the glucocerebrosidase gene have been identified in patients with GD, producing an enzyme which is catalytically abnormal, rapidly degraded, or truncated. Although there is a wide variation in clinical expression in GD which cannot generally be explained by the genotype alone, the four most frequently identified mutations are to some degree predictive of the course of the disease. ${ }^{36}$ For example, patients having at least one N370S mutation, whether as homozygotes or compound heterozygotes, are at a very low risk for primary neurological involvement, while those who are homozygotes for the L444P mutation usually present with neurological abnormalities. $^{36}$ In one hydrops fetus a

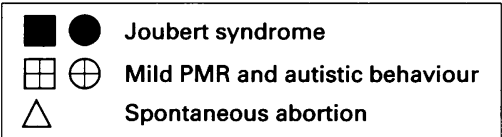

Figure 1 Pedigree of the family. Results of mutational analysis in relation to Gaucher disease type 1 are presented.

Gluc $^{*}=\beta$-glucocerebrosidase activity in fibroblasts expressed as $\mathrm{nmol} / \mathrm{h} / \mathrm{mg}$ protein (normal range 120-400); NA-not available; $P M R=$ sychomotor retardation. 
complete absence of glucocerebrosidase was caused by homozygosity for a null mutation.

This report describes an unusual association of GD type 1 and JS in a nonconsanguineous family of Indonesian and white Dutch ancestry (fig 1). The proband, patient II.1, was born at term with a birth weight of $3550 \mathrm{~g}$, a length of $54.5 \mathrm{~cm}$, and a head circumference of $38.5 \mathrm{~cm}$ ( $>98$ th centile). The diagnosis of JS was made by the presence of features including episodic hyperpnoea/apnoea, agenesis of the cerebellar vermis and corpus callosum, hydrocephalus, and chorioretinal colobomata. Severely delayed psychomotor development and generalised seizures were the major clinical features until death at the age of 4 years. Unexpectedly, lysosomal enzyme investigations showed a severe deficiency of glucocerebrosidase activity in cultured skin fibroblasts. Molecular studies showed compound het erozygosity N370S/L444P, the most common genotype in patients with GD type 1 in The Netherlands. Patient II. 3 was born after an uneventful pregnancy and delivery with normal weight, length, and head circumference. At the age of 2 years, she had retarded mental development and autistic behaviour. Magnetic resonance imaging of the brain was normal at 7 years. At this age, she had no clinical features of GD type 1, except for mild hepatosplenomegaly. Like her older brother, she appeared to have deficient glucocerebrosidase activity associated with compound heterozygosity for GD type 1 . In the third patient (II.4) at 16 weeks of gestation hydrocephalus was detected by ultrasound. Birth weight was $3220 \mathrm{~g}$ and head circumference $39.3 \mathrm{~cm}$ ( $>98$ th centile). The patient fulfilled the diagnostic criteria for JS and he died at the age of 8 month; no material was available for analysis.

This non-consanguineous family with two boys affected by JS and a girl with autistic behaviour was identified to have the most frequent genotype of GD type 1 in the Dutch population. ${ }^{6}$ The presence of a severe neurological disorder such as JS and autistic behaviour cannot be explained by the N370S/ L444P GD genotype alone. To address the possibility that the features of GD type 1 have been masked by the early onset of severe manifestations of JS, we investigated eight additional patients with JS. In these patients, we found a normal glucocerebrosidase activity in fibroblasts. These results suggest that the JS and GD loci do not (simply) coincide.

The most likely explanation for the coexistence of the two disorders in one person is the independent association of GD and JS. In this case, our observation may be unique, since the statistical probability of this event is extremely small in a non-consanguineous and interracial relationship. The incidence of GD type 1 is estimated at 1:50 $000^{3}$ and no more than 100 cases of JS have been reported. Therefore, it may be worth considering other explanations. In this respect it is of interest to note the large clinical variability among GD patients with identical mutations, even within families. ${ }^{7}$ All patients with GD types 1,2 , and 3 have significant levels of residual glucocerebrosidase activity (3-8\% of those in controls Kleijer and Aerts, unpublished data), with the exception of a neonatal variant of GD with prenatal onset of fetal hydrops. ${ }^{4}$ Although our patients have a residual activity of $3-8 \%$ in fibroblasts, it remains possible that a complete knock out of glucocerebrosidase activity is present in some tissues, for example, the central nervous system in patient II. 1 (but not in patient II.3) by an as yet unknown factor, interacting with the transcription or translation of the gene or with the enzyme activity.

A VAN ROYEN-KERKHOF B T POLL-THE

University Children's Hospital "Het Wilhelmina Kinderziekenhuis", Nieuwegracht 137, 3512 LK Utrecht, The Netherlands

W J KLEIJER O P VAN DIGGELEN

Department of Clinical Genetics, University Hospital,

Erasmus University, Rotterdam, The Netherlands

J M F G AERTS

Department of Biochemistry, Academic Medical

Centre, University of Amsterdam, The Netherlands

$\mathrm{J} J$ HOPWOOD

Department of Chemical Pathology, Women's and

Children's Hospital, North Adelaide, Australia

F A BEEMER

Clinical Genetics Center Utrecht and Department of Clinical Genetics, University Children's Hospital

"Het Wilhelmina Kinderziekenhuis", Utrecht,

The Netherlands

1 Saraiva JM, Baraitser $M$. Joubert syndrome: a review. Am F Med Genet 1992;43:726-31

2 Pellegrino JE, Lensch MW, Muenke M, Chance PF. Clinical and molecular analysis in Joubert syndrome. Am $¥$ Med Genet 1997;72:59-62. syndrome. Am $\mathcal{F}$ Med Genet 1997;72:59-62.

3 Beutler E, Grabowski GA. Gaucher disease. In lar bases of inherited disease. 7 th ed. New York: McGraw-Hill, 1995:2641-70.

4 Tayebi N, Cushner SR, Kleijer W, et al. Prenatal lethality of a homozygous null mutation in the human glucocerebrosidase gene. $A m \Im \mathrm{Med}$ Genet 1997;73:41-7.

5 Sidranski E, Sherer DM, Ginns EI. Gaucher disease in the neonate: a distinct Gaucher phenotype is analogous to a mouse model created by targeted disruption of the glucocerebrosidase gene. Pediatr Res 1992;32:494-8.

6 Boot RG, Hollak CEM, Verhoek M, et al. Glucocerebrosidase genotype of Gaucher patients in the Netherlands: limitations in prognostic value. Hum Mutat 1997;10:348-58.

7 value. Hum Mutat 1997;10:348-58. Gaucher disease in one family: mutational studies and clinical update. $\mathcal{F}$ Pediatr 1994;125 919-21.

\section{BOOK REVIEW}

If you wish to order or require further information regarding the titles reviewed here please write to or telephone the $B M$ Bookshop, PO Box 295, London WC1H 9JR. Tel 0171383 6244. Fax 01713836662 Books are supplied post free in the UK and for BFPO addresses. Overseas customers should add $15 \%$ for postage and packing Payment can be made by cheque in sterling drawn on a UK bank or by credit card (Mastercard, Visa, or American Express) stating card number, expiry date, and full name. (The price and availability are occasionally subject to revision by the Publishers.)

Lancelot Hogben Scientific Humanist. An Unauthorised Autobiography.

Editors Adrian and Anne Hogben. (Pp xvii + 254; f14.95.) Suffolk, UK: The Merlin Press. 1998. ISBN 0850364701 .

Unauthorised autobiographies are rare, but the title is arresting rather than accurate. After Hogben's death Professor G P Wells, who wrote an extensive obituary in the Biological Memoirs of the Royal Society, at- tempted to get a mass of papers, which was clearly an unfinished autobiography, published. Ten years ago I met Hogben's elder son, Adrian, who had retired to near Bars Harbor, and made an equally unsuccessful attempt to interest Oxford University Press. This unfinished and extensively annotatedळ manuscript had limitations as a profitable venture unless extensively edited, when $r:$ feared it would lose more than could be gained. However, it has been edited withour losing the forceful elegance of his prose and the various repetitive sections have been $\overline{\bar{N}}$ welded into a seamless narrative. Additions include many photographs taken by Adrian, although only a small representation of hise extensive collection after, when a child, he had been given a camera by Frank Bodmer, $\bigcirc$ coauthor of The Loom of Language. It alsoincludes an essential, but all too brief, appen- $\omega$ dix of the cast.

Hogben, like Newton, started life as a veryő premature baby. His parents, who devotedw their lives to missionary work in Portsmouth, and later London, espousing a hellfire brandof fundamental Methodism, provided ance unusual physical and intellectual environ- $\sigma$ ment which changed abruptly after he went음 to Cambridge with a scholarship to Trinity.While there the war started, providing anz extraordinary series of experiences. $\mathrm{He}$ became a Quaker under the influence of the $\frac{\mathbb{D}}{3}$ distinguished trio of Doncaster, Barcroft, and Eddington-a geneticist, a physiologist, and an astrophysicist. His attempts to study medicine were interrupted by voluntaryce work, mainly building huts, among those dis-possessed of their land in Flanders, then a quagmire of trenches and shell holes. His uncompromising integrity led him, after various duties with the Friends' Ambulance Unit⿳⺈ in France, including giving anaesthetics, to을 prison in London, the fate of many objectors to war. While there he was deprived of books, pencil, or paper. Although his medical career $=$ was interrupted his further education allowed him to acquire an extensive knowledge and? experience of every living thing he could observe, animal or plant, large or small. His persistence overcame numerous obstacles, initially including poverty, and later episodic thyrotoxicosis, eventually moderated by a five hour operation to remove a retrosternal? goitre.

His first major discovery was made after studying over a thousand sections of the tes- $D$ tis of the cockroach: at last he caught chromosomes in the act of side to side synapsis, resolving the conflict between Morgan's. interpretation of recombination and previous $N$ observations showing end to end synapsis. N Morgan visited him. Bateson was only converted to crossing over as an explanation of disturbed cosegregation some years later in Morgan's laboratory, some 20 years after he and Punnett had first described it.

Later his career took him to Edinburgh, Montreal, Cape Town, The London School of Economics, and Aberdeen, from where he eventually got to Birmingham via trans-零 Siberian railway after lecturing in Oslo when the Germans invaded. As an active opponent< of their eugenic activities and supporter of Jewish scientists, he was on the blackest ofo black lists. With his elder daughter Sylvia he escaped to Sweden, eventually returning via Russia and the USA to become Professor of Zoology in Birmingham, only to be invited to head the Medical Statistics division of the Army work in London during the blitz. He finally returned to Birmingham, where 